\title{
FORMAÇÃO CONTÍNUA PARA PROFESSORES SEM FORMAÇÃO PEDAGÓGICA: UM ESTUDO DE CASO COM PROFESSORES DE EDUCAÇ̃̃O FÍSICA DA ESCOLA PRIMÁRIA N. 74 DANGEREUX, NA PROVÍNCIA DE MALANJE-ANGOLA
}

\author{
EDUCACIÓN CONTINUA PARA PROFESORES SIN FORMACIÓN PEDAGÓGICA: \\ ESTUDIO DE CASO CON PROFESORES DE EDUCACIÓN FÍSICA DE LA ESCUELA \\ PRIMARIA N.74 DANGEREUX, PROVINCIA DE MALANJE-ANGOLA
}

\author{
CONTINUOUS EDUCATION FOR TEACHERS WITHOUT PEDAGOGICAL \\ EDUCATION: A CASE STUDY WITH PHYSICAL EDUCATION TEACHERS AT \\ PRIMARY SCHOOL N. 74 DANGEREUX, IN THE PROVINCE OF MALANJE- \\ ANGOLA
}

\author{
João Isarael CABAMBA ${ }^{1}$ \\ Cristina YANES-CABRERA ${ }^{2}$ \\ Miguel Ángel BALLESTEROS MOSCOSIO ${ }^{3}$
}

\begin{abstract}
RESUMO: A Educação Física é uma disciplina composta por atividades físicas planejadas e estruturadas com o propósito de melhorar a saúde física, e a docência nesta área requer formação profissional assim como nas demais áreas do conhecimento. O objetivo deste artigo foi analisar as competências pedagógicas dos professores de Educação Física de uma escola primária no município de Malanje, em Angola. Para tanto, utilizou-se uma abordagem qualiquantitativa por meio da aplicação de questionário, observação e entrevista a oito professores, 29 alunos e a diretora da escola. Constatou-se a presença de professores sem formação específica conduzindo as aulas de Educação Física, alunos desmotivados e uma direção empenhada em fortalecer seu corpo pedagógico tendo em vista o perigo em potencial que profissionais despreparados podem causar tanto aos alunos como para a Escola. Por estes motivos, este artigo propôs um programa de formação contínua aos professores a fim de melhor prepará-los para seus cargos.
\end{abstract}

PALAVRAS-CHAVE: Educação física. Metodologia de ensino. Formação pedagógica. Professores. Escola.

RESUMEN: La Educación Física es una asignatura compuesta por actividades fisicas planificadas y estructuradas con el propósito de mejorar la salud física, y la docencia en esta área requiere de una formación profesional así como en otras áreas del conocimiento. El objetivo de este artículo fue analizar las competencias pedagógicas de los profesores de

${ }^{1}$ Instituto Superior Politécnico de Malanje (ISPM), Malanje - Angola. Professor do Departamento de Ciências da Educação e Diretor Geral Adjunto. ORCID: https://orcid.org/0000-0002-0507-9833. E-mail: quitumina@gmail.com

${ }^{2}$ Universidad de Sevilla (US), Sevilla - Andalucía - Espanha. Professora do Departamento de Teoria e História da Educação e Pedagogia Social. ORCID: https://orcid.org/0000-0003-1374-137X. E-mail: yanes@us.es

${ }^{3}$ Universidad de Sevilla (US), Sevilla - Andalucía - Espanha. Professor do Departamento de Teoria e História da Educação e Pedagogia Social. ORCID: https://orcid.org/0000-0001-9522-4303. E-mail: miguelanba@us.es

RIAEE - Revista Ibero-Americana de Estudos em Educação, Araraquara, v. 16, n. 4, p. 2279-2294, out./dez. 2021. e-ISSN: 1982-5587 
Educación Física de una escuela primaria del municipio de Malanje, Angola. Para ello, se utilizó un enfoque cualitativo-cuantitativo mediante la aplicación de un cuestionario, observación y entrevistas a ocho docentes, 29 alumnos y el director de la escuela. Se constató la presencia de docentes sin formación específica ante las clases de Educación Física, alumnos desmotivados y una dirección comprometida con el fortalecimiento de su cuerpo pedagógico ante el potencial peligro que los profesionales desprevenidos pueden ocasionar tanto a los alumnos como a la Escuela. Por estas razones, este artículo propuso un programa de educación continua para docentes con el fin de prepararlos mejor para sus puestos.

PALABRAS CLAVE: Educación física. Metodología de la enseñanza. Formación pedagógica. Profesores. Colegio.

ABSTRACT: Physical Education is a discipline composed of planned and structured physical activities with the purpose of improving physical health, and teaching in this area requires professional training as well as in other areas of knowledge. The aim of this article was to analyze the pedagogical skills of Physical Education teachers at a primary school in the municipality of Malanje, Angola. For that, a qualitative-quantitative approach was used through the application of a questionnaire, observation and interviews to eight teachers, 29 students and the school principal. It was found the presence of teachers without specific training leading Physical Education classes, unmotivated students and a direction committed to strengthening their pedagogical body in view of the potential danger that unprepared professionals can cause both to students and to the School. For these reasons, this article proposed a continuing education program for teachers in order to better prepare them for their positions.

KEYWORDS: Physical education. Teaching methodology. Pedagogical training. Teachers. School.

\section{Introdução}

A República de Angola é um país litorâneo situado na África Austral, entre a Namíbia, Zâmbia e a República Democrática do Congo, com uma população estimada em 24 milhões de habitantes (censo de 2014). A capital situa-se em Luanda e o país segue uma divisão político-administrativa em 18 províncias (Bengo, Benguela, Bié, Cabinda, Cuando-Cubango, Cunene, Huambo, Huíla, Kwanza Sul, Kwanza Norte, Luanda, Lunda Norte, Lunda Sul, Malanje, Moxico, Namibe, Uíge, Zaire), 163 municípios e 475 comunas (ANGOLA, 2014).

De 1975 a 2002, Angola enfrentou um conflito armado entre os movimentos de libertação nacional (que angariavam a independência de Portugal). Tendo durado cerca de 30 anos, quando iniciou seu processo de recuperação e reconstrução do país, foram necessários esforços também para a reconstrução da infraestrutura escolar (DW, 2021).

Neste sentido, apesar dos esforços institucionais em regular e padronizar o sistema educativo angolano e com a implementação da Reforma Educativa no país em 2004, o 
número de professores ainda era insuficiente para ensinar o grande número de alunos que frequentavam as escolas. Por isso, tendo em vista essa necessidade de aumentar o número de professores, o Ministério da Educação de Angola passou a alocar os docentes com e sem formação pedagógica, formados em cursos de ensino gearal (II Ciclo) e licenciaturas, para ocupar os cargos disponíveis de modo generalista. Considerando que o ensino primário em Angola segue o modelo de monodocência, no qual um professor leciona todas as disciplinas, incluindo a de Educação Física, o ensino desta disciplina passou para as mãos de profissionais sem formação específica na área (CARDOSO; FLORES, 2009).

Considerando que, em 1977, Angola dispunha de cerca de 25 mil professores ensinando no ensino primário (ANGOLA, 1978), em 2019 estimava-se que eram 200 mil professores para ensinar mais de dois milhões de crianças em idade escolar (TCHALYONGO, 2019).

O maior impacto tangível do Novo Sistema de Educação traduziu-se na grande afluência da população às escolas, pois, se, em 1974, estudavam cerca de meio milhão de angolanos, em 1980, esse número superava os 1,8 milhões. Não foi possível manter esses indicadores, pois o país, apesar da conquista da independência, continuou em guerra, com consequências nocivas [...] que se refletiram nas infraestruturas escolares já que inúmeras escolas foram destruídas (CARDOSO; FLORES, 2009, p. 657).

O professor é o principal ator no processo de transmissão dos conhecimentos, é o indivíduo motivador e cativante que alavanca o processo de ensino-aprendizagem, despertando nos alunos o espírito democrático e a curiosidade em querer saber mais sobre as coisas que o circundam.

Para Ott et al. (2011, p. 338):

O professor é peça-chave no processo de ensino-aprendizagem, e no desenvolvimento de qualquer programa acadêmico, possui grande responsabilidade em seu trabalho: desenvolver conhecimentos, habilidades e atitudes, e dotar o aluno de competência visando o seu rendimento escolar.

Segundo Roldão (2007, p. 94), “a função do professor se caracteriza pela ação de ensinar, sendo que o conceito de ensinar, não é definido de modo simples e fácil, pois há diferença entre um professar saber fazer os outros aprenderem alguma coisa".

$\mathrm{Na}$ visão deste autor, o professor é o indivíduo capaz de mediar os conhecimentos ou conteúdos a serem ministrados para os alunos, ou seja, ser professor é ter a capacidade de transformar, ensinar, instruir, educar, acompanhar e até mesmo desenvolver no indivíduo a capacidade de refletir, analisar e criticar certos comportamentos ou situações sociais adversas. 
Desta maneira acontece com todas as áreas de conhecimento, e na Educação Física não deveria ser diferente, já que, para Zunino (2008, p. 9), a Educação Física:

É uma das formas mais eficientes pela qual o indivíduo pode interagir e, também é uma ferramenta relevante para a aquisição e aprimoramento de novas habilidades motoras e psicomotoras, pois é uma prática pedagógica capaz não somente de promover a habilidade física como a aquisição de consciência e compreensão da realidade de forma democrática, humanizada e diversificada, pois nesta etapa educacional a educação física deve ser vista como meio de informação e formação para as gerações.

Conquanto, a educação física é uma disciplina que visa estimular em seus praticantes a boa postura física, o relaxamento muscular e a socialização entre os praticantes. Entretanto, para Neira (2003), a disciplina de educação física, dentro do contexto escolar, tem sido alvo de críticas e descrença nos últimos anos quanto aos conteúdos que ensina e à própria relevância na formação dos alunos. A educação física vem perdendo espaço e tornando-se para muitos alunos, professores e dirigentes escolares em uma disciplina dispensável e sem importância.

Segundo Barbosa (2001, p. 185) "muitos professores e alunos não se interessam com a real finalidade da disciplina de educação física, veem-na apenas como uma aula de recreação". Sendo assim, a ausência de profisssionais devidamente formados para ministrarem as aulas de Educação Física nas escolas da província de Malanje, motivou a abordagem do tema neste estudo que carece de uma solução urgente.

Por isso, este artigo objetiva refletir acerca do perfil profissional dos professores de Educação Física do ensino primário da escola n. 74 de Dangereux, na província de Malanje, em Angola. Como objetivos específicos, incluem-se: (a) discorrer sobre as competências profissionais dos professores de Educação Física; (b) analisar o nível de competências profissionais dos professores de Educação Física da escola n. 74 de Dangereux; (c) abordar as diferentes formas dos professores sem formação específica que lecionam Educação Física; e, (d) sugerir um programa de formação contínua aos professores sem formação específica que lecionam a disciplina de Educação Física na escola primária n. 74.

Quanto aos procedimentos metodológicos, trata-se de uma pesquisa quali-quantitativa com abordagem mista por meio do uso de questionário, entrevistas e guia de observação. Os resultados deste estudo podem auxiliar os professores da área de educação física das escolas primárias de Malanje, e outras regiões do mundo, a manterem sua qualificação com vistas ao conteúdo e à qualidade das aulas que ministram. 


\section{Competências pedagógicas}

Nos últimos anos, a palavra competência entrou para as discussões acadêmicas ou educacionais, associada a diferentes instâncias de compreensão: no nível da pessoa (a competência do indivíduo), das organizações (as core competences) e dos países (sistemas educacionais e formação de competências).

No que diz respeito à docência, referem-se às competências pedagógicas em uma área específica, que compreendem o domínio dos conhecimentos básicos, bem como a presença de uma experiência profissional de campo e política, uma vez que tanto professor como aluno são cidadãos que carregam consigo suas visões de pessoa, do mundo, da sociedade, da cultura e da educação (MASETTO, 2012).

Segundo Masetto (2012, p. 32), a:

Competência na área pedagógica é o ponto mais carente dos professores, quando se fala em profissionalismo na docência e abrange o domínio do conceito de processo de ensino-aprendizagem, concepção e gestão de currículo, interligação das disciplinas como componentes curriculares, compreensão da relação professor-aluno e aluno-aluno, teoria e prática educacional, concepção do processo avaliativo e suas técnicas para a reciprocidade e o planejamento como atividade educacional.

Sacristán (1995, p. 63) afirmou que "é também consensual a ideia de que as competências adquiridas na formação inicial de professores acabam por ser insuficientes e a componente prática constante na formação inicial de professores é muito limitada, não respondendo às verdadeiras necessidades dos futuros docentes". Em outras palavras, "são as capacidades que qualificam os indivíduos para exercerem certas funções" (PAQUAY et al., 2006, p. 21).

A próxima seção discorre especificamente sobre o papel do professor de Educação Física que, quando atua dentro de sua formação inicial, contribui para a saúde física, mental e psicomotora dos alunos no contexto em que está inserido.

\section{O professor de Educação Física}

Considerando que a Educação Física é uma disciplina composta por atividades físicas planejadas e estruturadas com o propósito de melhorar ou manter o condicionamento e a saúde física, tida como uma área do conhecimento humano ligado a saúde e ao desenvolvimento mental e corporal, a docência nesta área requer formação profissional, assim 
como nas demais áreas do conhecimento que demandam por saberes, competências e habilidades próprias ao seu ofício.

Por isso, é importante que o profissional de Educação Física tenha o domínio dos conteúdos teórico-práticos que ministra e saiba aplicá-los de acordo com o meio em que está inserido e o tipo de alunos que possui conforme as características pessoais de cada um.

Slomski (2008, p. 8) esclareceu que:

Um dos papéis do professor é aperfeiçoar sua profissão a partir do domínio de saberes, da aquisição de competências e do aperfeiçoamento de habilidades para agir individual e coletivamente no exercício da mesma, existindo competências profissionais que se destacam nos ambientes corporativos, entre elas a comunicação, a liderança e o planejamento.

Entretanto, além de a Educação Física ser uma disciplina na grade curricular, ela inclui também outra importância transversal ao lidar com a saúde mental, física e psicomotora da criança. Quando não se tem um professor profissional, competente na área de educação física, notar-se-ão adversidades nos alunos quando das práticas, como, por exemplo, no desenvolvimento físico e psicomotor dos alunos, pois os bons ensinamentos dos professores, em muitos casos, se refletem nas boas práticas dos alunos (KÜHL, 2013).

Alguns ganhos culturais e corporais foram incorporados, ao longo dos anos, pela Educação Física em seus conteúdos, tais como: o esporte, o jogo, a dança, a ginástica e a luta. Estes têm em comum a representação corporal, com características lúdicas de diversas culturas humanas.

Goodwin e Watkinson (2000, p. 144) enfatizaram que:

As aulas de educação física escolar ajudam na independência, autoconfiança, melhora na postura física dos alunos praticantes, melhora no senso dos alunos, melhora na autoconfiança dos alunos inibidos, melhora no senso para conviver e trabalhar em grupo e faz ter amigos, colegas de classe com mais facilidade.

O papel do professor de Educação Física não é, portanto, tratar apenas dos aspectos pedagógicos dos conteúdos culturais e curriculares relacionados às práticas corporais, que possam influenciar na aprendizagem dos alunos. Exige-se também um profissional competente, que possua tanto o conhecimento da área científica como do contexto no qual atua. Desta forma, torna-se evidente a necessidade de reconstruir e atualizar a perspectiva dos professores acerca das competências profissionais de forma a serem capazes de responder aos novos desafios da área. 


\section{Metodologia}

Esta pesquisa seguiu uma abordagem quali-quantitativa mista com o uso de um guia de observação das práticas de professores e alunos, um questionário e um roteiro de entrevista na escola primária n. 74 Dangereux, na província de Malanje-Angola.

A população analisada incluiu as seguintes classes de ensino primário: $4^{\mathrm{a}}, 5^{\mathrm{a}}$ e $6^{\mathrm{a}}$ séries. Nesta pesquisa, a amostra foi de 38 sujeitos, dentre o corpo diretivo, os professores e alunos, o que corresponde a $26 \%$ da população da escola pesquisada.

Tabela 1 - População e amostra analisada

\begin{tabular}{c|c|c|c}
\hline Participantes & População & Amostra & Porcentagem \\
\hline Corpo Diretivo & 1 & 1 & $100 \%$ \\
Professores & 10 & 10 & $100 \%$ \\
Alunos & 135 & 29 & $21,5 \%$ \\
\hline TOTAL & $\mathbf{1 4 6}$ & $\mathbf{3 8}$ & $\mathbf{2 6 \%}$ \\
\hline
\end{tabular}

Fonte: Elaborado pelos autores

A técnica de observação do ensino baseou-se na coleta de informações sobre as aulas de Educação Física e todos os elementos nela envolvidos. Na medida em que o professor ia lecionando, realizou-se a observação direta e anotações em uma guia sobre o que acontecia. Esta técnica foi aplicada sobre os professores e alunos, dentro e fora das salas de aulas, como meio de averiguar as práticas de ambos durante as aulas.

O questionário foi utilizado para a obtenção de informações sobre o tema em estudo, considerando as contribuições e as opiniões dos alunos em relação às competências profissionais dos professores de Educação Física, e dos próprios professores sobre sua atuação. Esta técnica foi utilizada para a coleta de dados quantitativos (resultados estatísticos) tendo em vista a necessidade de expressão anônima, por parte de alunos e professores, de sentimentos, pensamentos, desejos, motivações sobre a disciplina de educação física. Apesar de o questionário ser um instrumento de coleta de dados muito usado em pesquisas qualitativas, foram realizadas perguntas de múltipla escolha, ou seja, fechadas, permitindo aos inqueridos sentirem-se livres ao expressarem suas opiniões.

A entrevista permitiu obter informações sobre as políticas da escola em relação à obtenção de professores competentes em Educação Física, a interação e a socialização dos alunos nas aulas de Educação Física e a importância dela na vida dos alunos. Esta técnica foi aplicada apenas à diretora da escola em questão por ser uma forma de colher informações de 
forma direta e fidedigna, possibilitando, assim, maior credibilidade e confiabilidade às informações levantadas.

A próxima seção apresenta a análise e a interpretação dos resultados deste estudo na escola n. 74 Dangereux, na província de Malanje-Angola.

\section{Apresentação, análise e interpretação dos resultados}

Malanje é uma das províncias de Angola situada na região norte do país, conta com uma população estimada de 1.108264 habitantes e área territorial de $98.320 \mathrm{~km}^{2}$, constituida por 14 municipios e possui cinco Magistérios de formação de professores, nomedamente: Cdte Cuidado (pública), Jérónimo Neto ( pública), ADPP ) Ajuda de Desenvolvimento de Povo para Povo (pública), S. João Paulo II (comparticipada) e S. José de Cluny ( comparticipada) das quais apenas uma é de formação específica de profissionais de Educação Física, chamada Escola Magistério Jerónimo Neto, que abriu recentemente as portas em 2016 na localidade do Ngolo, bairro da Cahala.

O membro representante da Direção da escola é do sexo feminino e com idade compreendida entre 35-50 anos. Dos dez professores participantes, quatro são do sexo feminino e seis do sexo masculino, com idades entre 20-50 anos, sendo sete com formação no Ensino Geral (sem formação em metodologia de ensino, e tampouco em Educação Física), um com Licenciatura em Psicologia pela Escola Superior Politécnica de Malanje (ESPM) e dois com Magistério, pela escola de formação de professores Comandante Cuidado, nos cursos de Geografia e História. Dos alunos, 103 eram do sexo masculino e 27 do sexo feminino, com idades entre 8-11 anos.

O subsistema do Ensino Geral é constituído por: ensino primário de seis classes (base obrigatória, isto da $1^{\mathrm{a}}$ a $6^{\mathrm{a}}$ Classes) e pelo ensino secundário, que integra dois ciclos, com a duração de três anos cada (assim descrito: I Ciclo, das $7^{\mathrm{a}} 9^{\mathrm{a}}$ classes e II Ciclo geral, da $10^{\mathrm{a}}$ a 12 Classes). O subsistema de Formação de Professores estrutura-se nos seguintes níveis, com a duração de quatro a seis anos, respectivamente: Médio Normal ( da $10^{\mathrm{a}}$ a $13^{\mathrm{a}}$ Classes) e Superior Pedagógico ( do $1^{\circ}$ a $4^{\circ}$ ano “ formação inicial”. Compreende ainda ações que se enquadram na formação permanente: a agregação pedagógica, aperfeiçoamento e treinamento para a "formação contínua" (CARDOSO; FLORES, 2009).

As observações foram realizadas nas aulas da $4^{\text {a }}$ série segundo parâmetros relacionados à motivação do professor e dos alunos, e aspectos psicológicos, além das práticas de desenvolvimento das aulas e de seu término, conforme apresentado no Quadro 1. 
Quadro 1 - Resultados das observações das aulas de Educação Física da $4^{\mathrm{a}}$ série

\section{Observações}

\section{MOTIVAÇÃO:}

- O professor não cumpriu com a parte inicial motivacional, geralmente composta por alongamentos, aquecimento, ou outro tipo de preparação do organismo para enfrentar as atividades práticas;

- Faltou por parte de alguns professores um acompanhamento específico, orientando cada aluno sobre os equipamentos a serem usados e a posição correta e recomendável para evitar lesões.

\section{PSICOLÓGICA:}

- O professor não manteve um diálogo antes de iniciar a aula, a fim de preparar seus educandos psicologicamente sobre a progressão dos exercícios, orientando e exemplificando a natureza de cada exercício;

- Outrossim, não explicou aos alunos as vantagens, benefícios e a importância que as aulas de educação física podem trazer para suas vidas.

DESENVOLVIMENTO:

- Notou que muitos alunos faziam as práticas dos exercícios físicos de forma desorientada, ou sem uma metodologia própria, bem como uma organização da turma por idades;

- Os alunos não mostravam disposição em querer participar ativamente das aulas de educação física;

- A falta de orientação do tempo para cada exercício;

- Em nenhum momento os professores procuraram interagir com os alunos que apresentaram alguma fadiga ou cansaço prematuro para saber as causas, ou o real motivo de suas indisposições;

- Faltou, por parte de alguns professores, a capacidade de ter controle emocional e evitar se estressar, ou agir de modo arrogante ou nervoso quando questionados ou sugeridos pelos alunos sobre a aula;

- Não foram realizadas atividades práticas, apenas exercícios livres, como: corridas, pular, girar, curvar, sentar, levantar e baixar.

CONSOLIDAÇÃO:

- Não se observou ao final das aulas práticas os professores orientando seus alunos a fazerem exercícios de relaxamento (que contribuem para descontrair as veias);

- O professor não se assegurou das condições que proporcionam o retorno dos alunos à calma, tirando-os dos ânimos exaltados, do estresse e da fadiga.

Fonte: Elaborado pelos autores

Neste sentido, por antes não existir por parte dos professores condimentos motivacionais que levem as crianças a despertarem a vontade e o espírito interativo, a falta de ambientes saudáveis com brincadeiras lúdicas, que trazem nos alunos diversão em grupo ao mesmo tempo em que coincidem com o ensino-aprendizagem e uma palavra de consolo, são indícios de situações que podem deformar o estado físico das crianças, causando transtornos e consequências nocivas à vida no futuro visto que a prática de Educação Física deve ser vista como um catalizador para a saúde humana capaz de evitar doenças oportunistas.

No que se refere à entrevista realizada com a diretora da escola n. 74 Dangereux, na província de Malanje-Angola, em relação à importância da educação física no processo de ensino-aprendizagem, ela afirmou que: "a educação fisica para os meninos é importante porque eles fazendo poderão evitar muitas doenças, e também lhes vai ajudar na interação entre os colegas da mesma classe. Ainda assim, eles podem adquirir habilidades para desenvolverem práticas desportivas". 
No que diz respeito à análise dos professores em relação aos alunos que não fazem exercícios físicos, a diretora disse "que não é bom se abster das práticas de educação fisica porque estão sujeitos a contrair doenças por causa do sedentarismo, tais como a obesidade, diabetes, e outras que em nada ajudam no desenvolvimento ou crescimento da criança".

Ainda assim, sobre relatos de professores que não lecionam as aulas práticas de educação física, a diretora respondeu que "alguns professores da $4^{a}, 5^{a}$ e $6^{a}$ séries não lecionam com frequência os exercícios práticos em função de não possuírem formação específica em educação física, e isto faz com que as aulas sejam, em grande medida, teóricas e de atividades livres dos alunos, como: corridas, pular, saltar, baixar e girar".

Neste sentido, quanto aos professores que não possuem formação específica em Educação Física, mas que mesmo assim lecionam nessas aulas, a diretora afirmou que:

Grande número de professores aqui na instituição não têm formação pedagógica, tampouco específica ligada à educação física, possuem como habilitações literárias ensino geral, e isto tem causando dificuldades na gestão e qualidade do processo docente-educativo. Estas situações podem perigar o futuro das crianças e podem causar lesões ou sequelas nas crianças, porque para trabalhar com as crianças é preciso se ter muito cuidado, porque são seres inofensivos e frágeis. Precisa-se conhecer primeiro o corpo humano e seu funcionamento, para não causar lesões graves.

Além disso, no que se refere aos alunos que desvalorizam essa disciplina, a diretora argumentou: "temos tido diálogo permanente com os professores e encarregados de educação de modo a incentivá-los a participarem de todas as atividades letivas, escolares e extraescolares, porque assim eles aprendem de forma lúdica, e descobrem seus talentos escondidos para posteriormente aplicarem em suas vidas".

Questionada se a direção da escola tem implementado estratégias para incentivar os alunos que se abstêm das aulas de educação física, a diretora afirmou que:

Tem sim, mas temos implementado uma série de ações em colaboração com os encarregados de educação e professores das classes para que expliquem as vantagens das práticas de educação fisica em suas vidas e na contribuição de sua saúde. Embora sejam crianças, mas passamos sempre a informação a eles, de que a educação fisica faz ter boa saúde e crescer devidamente sem constrangimentos.

A preocupação da diretora em traçar estratégias para ultrapassar as dificuldades implícitas nos professores atuantes sem formação adequada na área de Educação Física e dos alunos sem interesse em fazer das aulas um lugar de prática e aprendizagem ficou clara. A escola deve ser vista como um local onde professores e alunos exerçam o desejo de querer 
praticar, aprender e conhecer as vantagens e a importância das aulas de Educação Física, assim como das demais disciplinas.

Considerando que os professores entrevistados nesta pesquisa seguem o modelo de monodocência de Angola, ministrando todas as disciplinas, o questionário aplicado levantou as razões da escolha da profissão, se a falta de uma formação específica em Educação Física tem trazido dificuldades, se os alunos participam das aulas, se usam métodos que visam a aprendizagem, se dão mais exercícios práticos ou teóricos, se já pensaram em ter uma formação específica, se conhecem a importância das aulas, por quais motivos os alunos participam das aulas de educação física e se já notaram desenvolvimento psicomotor em seus alunos.

Sobre as razões que os levaram à escolha desta disciplina, cinco professores foram peremptórios em responder que foi pela paixão por ensinar, um afirmou que faltavam outras escolhas de emprego e pelo fato de ver que a disciplina é fácil de ser manipulada, e dois assumiram que escolheram a profissão de professor pela luta por sobrevivência. Os desníveis das respostas apresentadas é de todo modo preocupante.

Dentre os dez professores questionados, três responderam sim em relação às dificuldades de ministrar as aulas estarem relacionadas à falta de uma formação específica em Educação Física, três responderam que não, dois responderam que "algumas vezes" e dois que "nem tanto". Sete professores responderam que os alunos valorizam e participam das aulas de Educação Física, enquanto que três professores respondeu que apenas alguns participam. $\mathrm{Na}$ visão dos professores, três responderam sim em relação à aplicação de métodos eficazes que visam a aprendizagem dos alunos nas aulas de Educação Física, para dois professores ele não tem aplicado tais métodos, enquanto que dois consideraram que nem sempre e três responderam que apenas em algumas vezes.

Quando inquiridos sobre realizarem uma formação específica em Educação Física, seis professores responderam que já pensaram no assunto, enquanto que apenas dois afirmaram não ter interesse. Estes dados demonstram que os professores possuem consciência da importância de se possuir, ou no caso, de obter uma formação específica na área a fim de agregar mais valor às aulas que ministram. Neste sentido, cinco professores responderam que tanto professor como alunos conhecem a importância das aulas de Educação Física para suas vidas, enquanto três responderam "nem tanto". Apesar disso, apenas dois professores afirmaram terem observado algum desenvolvimento psicomotor em seus alunos em decorrência das aulas de educação física, em contrapartida, seis responderam não terem observado tal diferença. 
Com relação aos motivos que levam os alunos a participarem das aulas de educação física, quatro professores responderam que é por saúde, três para obterem nota, e um por prazer.

Os alunos da $4^{\mathrm{a}}$ série (20 no total) foram questionados sobre gostarem das aulas: 18 responderam que sim, um respondeu que não e um respondeu que gosta um pouco. Além disso, todos os alunos responderam que são bem orientados pelo professor quanto à realização dos exercícios.

Com relação aos benefícios para a saúde, 18 alunos responderam que sim, a educação física traz benefícios, enquanto que dois responderam que não. Sobre o uso adequado de equipamentos nas aulas de educação física, 17 alunos responderam que o professor tem feito uso, enquanto três disseram que não.

A triangulação dos resultados obtidos por meio da aplicação dos questionários aos alunos e professores, da entrevista com a diretora da escola n. 74 Dangereux, na província de Malanje-Angola, e da observação das aulas evidenciou a influência, as vantagens e a importância das aulas de educação física aos participantes desta pesquisa.

Os dados quantitativos, levantados nos questionários, contradizem em parte os dados qualitativos obtidos pela guia de observação das aulas, visto que esta evidenciou uma forma pouco eficiente tanto de professores, em orientarem, motivarem, desenvolveram técnicas adequadas de exercícios e finalizarem as aulas com relaxamento e centramento dos alunos, como dos alunos, que se dispersavam ou faziam as atividades propostas apenas para cumprir com a obrigatoriedade da presença na disciplina.

Verificou-se a existência do desejo de ensinar e aprender, embora não em todos os professores e alunos, e tampouco por meio de técnicas, métodos e formas adequadas a alunos de diferentes idades e adaptadas às necessidades de cada um.

$\mathrm{Na}$ entrevista com a direção de escola, objetivou-se levantar as condições da aplicação das aulas de educação física, a formação dos professores e bem como a disponibilidade dos alunos em assistir as aulas. Constatou-se que a direção da escola tem criado mecanismos que visam dar soluções e ultrapassar as adversidades que a escola vem enfrentando, assumindo a necessidade de fazer parcerias e intercâmbios com a Escola de Formação de Professores de Educação em Malanje (EFPEFM) "Jerónimo Neto", a fim de obter alguns professores formados em educação física para melhorar o sistema de ensino-aprendizagem e incentivar os alunos a participarem de forma ativa das aulas e com maior adesão.

Neste sentido, demonstrou-se a necessidade de implementar um modelo de formação contínua aos professores de Educação Física da escola n. 74 para que possam se capacitar, 
mantendo conteúdos atualizados e se tornarem profissionais mais competentes e qualificados para o exercício de suas atividades letivas.

\section{Considerações finais}

Segundo a proposta deste artigo de levantar e analisar as competências pedagógicas dos professores de Educação Física da Escola Primária $n$. 74 Dangereux, na província de Malanje-Angola, observou-se a necessidade de uma maior valorização desta disciplina, tanto por parte dos professores como dos alunos que fizeram parte da amostra analisada. Tomandose seus devidos créditos, a Educação Física, assim como as demais disciplinas que fazem parte do currículo das escolas, possui benefícios visíveis tanto na saúde física dos alunos, como mental e emocional.

Sua prática, quando bem orientada e realizada, tende a evitar doenças posturais, como a cifose, dores de coluna, problemas de joelho, dentre outras, além de combater o sedentarismo ao levar seus praticantes a um caminho de efetivação teórico-prática que contribuem para a socialização dos alunos consigo (conhecendo e sentindo melhor seu corpo e seus limites físicos, mentais e emocionais), com os colegas (ao participarem de esportes e exercícios coletivos e em grupo) e com o professor (aprendendo a respeitar os mais velhos, assim como a contribuir quando possível com as atividades sugeridas).

Constatou-se também que a presença de professores sem formação específica na área de Educação Física é um perigo em potencial tanto para os alunos como para a Escola como um todo, visto que apenas profissionais capacitados e formados na área possuem conhecimentos necessários para a realização de um trabalho atento e zeloso junto aos alunos a fim de evitar lesões e não aumentar ainda mais a desmotivação dos alunos em relação à prática de atividades físicas, ou mesmo da própria disciplina durante o período escolar.

Neste sentido, perante os objetivos específicos deste estudo, no que se refere à análise do nível de competências profissionais dos professores de Educação Física da escola analisada, e frente ao fato de que os professores questionados não utilizam metodologias e métodos exigidos pedagogicamente e orientados ao ensino da disciplina apesar da escola estar fazendo um esforço para ultrapassar essa situação deficitária, sugere-se a aplicação de um modelo de formação contínua aos profissionais, baseado nos resultados da tese de doutorado apresentada ao Departamento de Teoria e História da Educação e Pedagogia Social da Universidad de Sevilla, conforme destacado a seguir: 
1- A direção da Escola n. 74, em Malanje, procure parcerias com a Escola de Formação de Professores em Educação Física de Malanje (EFPEFM);

2- As escolas passem a contratar professores formados em Educação Física para ministrarem a disciplina sem necessidade de adaptações, primando pelo nível de competências profissionais dos professores;

3- As escolas criem momentos de diálogos entre os professores e alunos a fim de se fazerem claras quanto à importância das aulas de Educação Física;

4- Os professores passem pelo processo de formação contínua em Educação Física; e,

5- As escolas disponibilizem uma oportunidade de formação contínua aos seus professores, de acordo com a disciplina que lecionam, respeitando a formação específica de cada profissional em sua área, inclusive na área de Educação Física.

A proposta completa de formação contínua para professores de Educação Física sem componente específica está descrita no Quadro 2, a seguir.

Quadro 2 - Proposta de formação contínua para professores de Educação Física sem formação específica

\begin{tabular}{|c|c|c|c|}
\hline Currículo & Público-alvo & Objetivos & Periodicidade (12 meses) \\
\hline Pedagogia geral & \multirow{14}{*}{$\begin{array}{l}\text { Professores das } \\
\text { Escolas do } \\
\text { Magistério } \\
\text { Comandante } \\
\text { Cuidado, São José } \\
\text { de Cluny, de } \\
\text { Educação Física e } \\
\text { da Associação } \\
\text { Desportiva de } \\
\text { Malanje e } \\
\text { professores da } \\
\text { Escola n.74, } \\
\text { II Ciclo Nicolau } \\
\text { Gomes Spencer, II } \\
\text { Cixclo Nossa } \\
\text { Senhora de } \\
\text { Fátima, Amílicar } \\
\text { Cabral, Rainha } \\
\text { Njinga a Mbandi, } \\
\text { Revo Francisco } \\
\text { Armando, S. } \\
\text { Pedro da IEPA e } \\
\text { Elimabe I. }\end{array}$} & \multirow{14}{*}{$\begin{array}{c}\text { - Formação dos } \\
\text { professores sem } \\
\text { formação específica } \\
\text { em Educação Física; } \\
\text { - Adequar o perfil } \\
\text { profissional dos } \\
\text { professores; } \\
\text { - Orientar os } \\
\text { professores a } \\
\text { melhores resultados } \\
\text { na base das } \\
\text { aprendizagens } \\
\text { significativas; } \\
\text { - Melhorar a imagem } \\
\text { das escolas } \\
\text { selecionadas para a } \\
\text { formação; } \\
\text { - Evitar transtornos } \\
\text { físicos e mentais que } \\
\text { comprometam a } \\
\text { saúde dos alunos. }\end{array}$} & \multirow{14}{*}{$\begin{array}{c}1^{\text {a }} \text { etapa: } \\
\text { - Formação de professores } \\
\text { de Educação Física ( } 6 \\
\text { meses, } 3 \text { vezes por semana } \\
\text { durante } 3 \text { horas de aulas); } \\
2^{\text {a etapa: }} \\
\text { - Práticas e oficinas } \\
\text { pedagógicas em Educação } \\
\text { Física (3 meses, } 3 \text { vezes } \\
\text { por semana, } 3 \text { horas de } \\
\text { aulas); }\end{array}$} \\
\hline Didática & & & \\
\hline Metodologia de Educação Física & & & \\
\hline $\begin{array}{c}\text { Método desportivo, jogos e } \\
\text { brincadeiras }\end{array}$ & & & \\
\hline $\begin{array}{c}\text { Expressões e outras modalidades } \\
\text { desportivas }\end{array}$ & & & \\
\hline $\begin{array}{l}\text { Psicologia do desenvolvimento e de } \\
\text { Educação }\end{array}$ & & & \\
\hline Higiene e Saúde & & & \\
\hline $\begin{array}{c}\text { Sistema de avaliação das } \\
\text { aprendizagens }\end{array}$ & & & \\
\hline Ética desportiva & & & \\
\hline $\begin{array}{c}\text { Formação pessoal, social e } \\
\text { deontológica }\end{array}$ & & & \\
\hline $\begin{array}{l}\text { Análise sociológica da educação, } \\
\text { gestão e administração escolar }\end{array}$ & & & \\
\hline Práticas e oficinas pedagógicas & & & \\
\hline $\begin{array}{l}\text { Práticas, seminário e estágio } \\
\text { pedagógico de Educação Física }\end{array}$ & & & \\
\hline $\begin{array}{l}\text { Cerimónia de fim de curso e } \\
\text { certificação dos professores pelas } \\
\text { escolas formadoras, da Direcção } \\
\text { Municipal e do Gabinete Provincial } \\
\text { de Educação. }\end{array}$ & & & \\
\hline
\end{tabular}

Fonte: Elaborado pelos autores 
Como limitação desta pesquisa, destaca-se a seleção da amostra que analisou apenas os alunos da $4^{\text {a }}$ série da Escola n. 74 quando poderia ter sido estendida a outras turmas. Assim, sugere-se que estudos futuros englobem outras turmas a fim de comparar as opiniões de alunos mais velhos, e mais novos, em relação à didática dos professores em questão. Igualmente, sugere-se que este tipo de estudo de observação e levantamento das práticas de professores sem formação específica seja realizado com professores de outras áreas de conhecimento a fim de verificar em que medida os mesmos tipos de comportamentos e pensamentos dos professores se repetem.

\section{REFERÊNCIAS}

ANGOLA. Ministério da Educação. Princípios de base para a reforma do sistema de educação e ensino na R.P.A. Luanda: Ministério de Educação, 1978.

ANGOLA. Consulado Geral no Porto. Províncias. 2014. Disponível em:

http://www.consuladogeralangola-porto.pt/pt/provincias. Acesso em: 21 set. 2021.

BARBOSA, I. P. Formação inicial em educação física: uma nova epistemologia da prática docente. Porto Alegre: Movimento ESEF/UFRGS, 2001.

CARDOSO, E. M. S.; FLORES, M. A. A formação inicial de professores em angola: problemas e desafios. In: CONGRESSO INTERNACIONAL GALEGO-PORTUGUÊS DE PSICOPEDAGOGIA, 10., 2009. Anais [...]. Braga: Universidade do Minho, 2009.

CARVALHO, V. O acesso a uma educação de qualidade é um direito. Unicef Angola, 2015. Disponível em: https://www.unicef.org/angola/educacao. Acesso em: 21 set. 2021.

DW. Made for minds. Frente para a Libertação do Enclave de Cabinda (FLEC). DW, 10 ago. 2021. Disponível em: https://www.dw.com/pt-002/frente-para-a-liberta\%C3\%A7\%C3\%A3odo-enclave-de-cabinda-flec/t-17418282. Acesso em: 21 set. 2021.

GOODWIN, D. L; WATKINSON, E. J. Inclusive physical education from the perspective of student with physical disabilities. Adapted Physical Activity Quarterly, v. 17, p. 144-160, 2000 .

KÜHL, M. R. O valor das competências docentes no ensino da Administração. Revista de Administração, v. 48, n. 4, dez. 2013.

MASETTO, T. Competências pedagógicas do professor universitário. São Paulo: Summus, 2012.

NEIRA, M. C. Educação física: desenvolvimento e competências. São Paulo: Phorte, 2003. 
OTT, E. et al. Relevância dos conhecimentos, habilidades e métodos instrucionais na perspectiva de estudantes e profissionais da área contábil: estudo comparativo internacional. Revista Contabilidade e Finanças, v. 22, n. 57, 2011. DOI: 10.1590/S151970772011000300007

PAQUAY, L. et al. (Dir.). Formando professores profissionais. Quais estratégias? Quais competências? Porto Alegre: ArtMed, 2006.

ROLDÃO, M. C. Formar professores: os desafios da profissionalidade e o currículo. Aveiro: Universidade de Aveiro, CIFOP, 2007.

SACRISTÁN, J. Profissão professor. In: NÓVOA, A. Consciência e ação sobre a prática como libertação profissional dos professores. Porto: Porto Editores, 1995.

\section{SLOMSKI, V. G. Saberes que fundamentam a prática pedagógica do professor de} ciências contábeis. São Paulo, 2008.

TCHALYONGO, K. Má qualidade da educação em Angola resulta da falta de vontade política do Governo. Voa Português, 20 out. 2019. Disponível em:

https://www.voaportugues.com/a/m\%C3\%A1-qualidade-da-educa $\% \mathrm{C} 3 \% \mathrm{~A} 7 \% \mathrm{C} 3 \% \mathrm{~A} 30-\mathrm{em}$ angola-resulta-da-falta-de-vontade-pol\%C3\%ADtica-do-governo/5131594.html. Acesso em: 21 set. 2019.

ZUNINO, A. P. Educação física: ensino fundamental, 6º-9․ Curitiba: Positivo, 2008.

\section{Como referenciar este artigo}

CABAMBA, J. I.; YANES-CABRERA, C.; BALLESTEROS MOSCOSIO, M. Á. Formação contínua para professores sem formação pedagógica: um estudo de caso com professores de Educação Física da Escola Primária n. 74 Dangereux, na Província de Malanje-Angola. Revista Ibero-Americana de Estudos em Educação, Araraquara, v. 16, n. 4, p. 2279-2294, out./dez. 2021. e-ISSN: 1982-5587. DOI: https://doi.org/10.21723/riaee.v16i4.15518

Submetido em: 17/07/2021

Revisões requeridas em: 15/08/2021

Aprovado em: 20/09/2021

Publicado em: 21/10/2021 